\title{
Evaluating the Knowledge and Awareness of Women's about the Nexus between Reproductive Health Problems and Gender Based Violence in North Western Ethiopia
}

\section{EYAYU Kasseye Bayu}

University of Gondar College of Social Sciences and Humanities https://orcid.org/0000-0002-81054478

Solomon Anteneh tegegne

University of Gondar College of Social Sciences and Humanities

Alemeneh Getaneh Mhretie ( $\sim$ alemenehgetaneh1@gmail.com )

\section{Research article}

Keywords: Knowledge, Awareness, Perceptions, Gender Based Violence, Reproductive Health

Posted Date: April 24th, 2020

DOI: https://doi.org/10.21203/rs.3.rs-24246/v1

License: (c) (i) This work is licensed under a Creative Commons Attribution 4.0 International License.

Read Full License 


\section{Abstract}

Background: Sexual and reproductive health is the base of peoples living. However, many reproductive health questions are left unanswered. Hence, this study intends to assess women's awareness and knowledge of reproductive health problems as a result of violence in North Western Ethiopia.

Methods: To attain the objective of this study, mixed research approach with cross sectional concurrent research design was employed. Survey questionnaires, interviewees, focus group discussion and document reviews were the data collection instruments used. The collected data was analyzed by descriptive statistics. The target of this study was ten (10) randomly selected districts with 415 women (women in reproductive age) being the unit of analysis.

Results: The result demonstrated that, $40 \%$ of respondents have an awareness of GBV and its effects on reproductive health, while $60 \%$ are unaware of the importance of the relationship. It also show (55.9\%) of the respondents reported they are aware $\mathrm{RH}$ problem can be due to violence, while $44.1 \%$ of as they were unaware. Concerning this awareness, $(40.5 \%)$ are aware of the problem of headaches, whereas (29.6\%) are aware of functional limitation and disability. Considering, psychological/mental health problems, $39 \%$ are aware of the problem of depression and anxiety, while $35.7 \%$ of the respondents reported awareness about post-traumatic stress disorder. Regarding awareness and perception of the sexual and RH problems, (36.1\%) of the respondents reported they have awareness about STI and HIV/AIDS, while $19.8 \%$ have no awareness. The study also showed that unwanted pregnancy, fetal injuries and cervical cancer problems reported by $31.3 \%, 25.5 \%$ and $25.3 \%$ respondents respectively. From the study findings, a significant number of respondents are aware of physical health problems rather than psychological and sexual RH problems. This implies even though women are aware of RH problems, they have little awareness that GBV causes RH problems.

Conclusion: The findings inferred a majority of the respondents reported no awareness about the types of gender based violence which leads to reproductive health problems. Therefore, the health care sector needs to make significant impact by publicizing and addressing violence against women to reduce $\mathrm{RH}$ problems.

\section{Background}

Reproductive health is a universal concern especially for women particularly during the reproductive years. Reproductive health is a fundamental component of an individual's overall health status and a central determinant of quality of life. However, many reproductive health questions are still unanswered $[1 ; 2]$. As the study elaborates, many reproductive health questions are still unanswered; a solid foundation of biological reproductive health knowledge must be understood before attempting to investigate more complex reproductive health problems [1]. A study showed that even though sexual and reproductive health is important to us all, at all stages of our lives, far too many people are denied their 
right to sexual and reproductive health [3]. The vast majority are poor women, men and young people in developing countries [4].

In many developing countries, most reproductive decisions are made by the men although it is as well the concern of women. Accordingly, about $45 \%$ and $35 \%$ of the respondents of the research done by [5] reported their husbands dominate the contraceptive use and maternal health service utilization decisionmaking. This indicates that reproductive decision-making is strongly affected by gender power relations. Yet little attention has been paid to the serious health consequences of abuse and the health needs of abused women and girls. Women who have experienced violence suffer from a range of reproductive health problems, often in silence. In a Mexican society, the forms of violence have impact negatively on women's reproductive health, yet a culture of silence as well as the lesser inclusion of indigenous groups in implementation and enforcement of public policies has caused an imbalance [6; 7].

The women's understanding of good reproductive health included three major themes which were expressed differently in the three communities. Their understanding included good physical and mental health, and underscored the need for activities promoting health. Their ability to reproduce and raise children, practice family planning and birth spacing, and go through pregnancy and motherhood safely were central to their reproductive duties and their social status. Finally, they saw reproductive health within the context of economic status, good marital relations and strength to cope with their lives. These findings point to the need to situate interventions in the life course of women, their health and that of their husbands and families; the importance of reproduction not only from a health services point of view, but also as regards women's roles and responsibilities within marriage and their families; and taking account of the harsh socio-economic conditions in their communities [8].

In Africa, where a large proportion of the world's forcibly displaced populations are found, the total disease burden due to reproductive morbidity is 44.5 per cent. Poor reproductive health related to sex and reproduction is due to key causal factors found within risky sexual behaviors, pregnancy, abortion and childbirth [9]. The low status of women in Ethiopia underpins, and often directly undermines each of the negatives. Most Ethiopian women lack the reproductive and social self-determination needed to exercise their reproductive rights a condition that in turn, perpetuates their low reproductive health and social status. Ethiopia's rates of maternal and newborn morbidity and mortality are among the highest in the world. Women traditionally enjoy little independent decision making on most individual and family issues, including the option to choose whether to give birth in a health facility or seek the assistance of a trained provider [10]. Lack of clear understanding and misperceptions about SRH combined with unsupportive cultural expectations about sexual life remain important constraints to young people's efforts of seeking such services. Absence of confidentiality, lack of privacy, feeling of shame, being identified by parents and other people, and health system factors such as lack of SRH services plus long waiting time were also important barriers to using SRH. Thus, SRHS programs for young people must address psycho-social, sociocultural and health service factors through culturally sensitive $\mathrm{SRH}$ education and service delivery approaches. Furthermore, an inclusive approach which involves parents is recommended in SRH education program [11]. 


\section{Methods}

\section{Study Site}

Ethiopia is situated in the Horn of Africa, it has nine regional states and two chartered city administrations. The Amhara region is one of the regional states in the Federal Democratic Republic of Ethiopia, located in north-west between $9^{\circ} 20^{\prime}$ and $14^{\circ} 20^{\prime}$ North latitude and $36^{\circ} 20^{\prime}$ and $40^{\circ} 20^{\prime}$ East longitude. Its land area is estimated at about 170,000 square kilometers. The Amhara Region borders Tigray in the North, Afar in the East, Oromiya in the South, Benishangul-Gumuz in the South-west and the country of Sudan in the west. Amhara is divided into 11 zones and 140 districts with about 3429 kebeles (the smallest administrative units). Decision-making power has recently been decentralized to districts and thus the districts are responsible for all development activities in their areas. The 11 administrative zones are: North Gondar, South Gondar, West Gojjam, East Gojjam, Awie, Wag Hemra, North Wollo, South Wollo, Oromia, North Shewa and Bahir Dar City special zone [12].

\section{Study Population}

Based on the 2007 census conducted by the Central Statistical Agency of Ethiopia (CSA), the Amhara Region has a population of $17,221,976$. Of which, $8,641,580$ were men and $8,580,396$ women; urban inhabitants' number $2,112,595$ or $12.27 \%$ of the population. Amhara region has an estimated density of 108.2 people per square kilometer. For the entire Region 3, 983,768 households were counted resulting in an average for the Region of 4.3 persons to a household, with urban households averaging 3.3 and rural households 4.5 people [13]. The results of the 2007 Population and Housing Census of CSA [14] showed the total population of Amhara region at 17.2 million. The size of the population increased by $25 \%$ from 1994 - 2007 representing an annual growth rate of 1.7 percent. The total fertility rate (TFR) of the region declined from 5.1 children per woman in 2005 to 4.2 in 2011[15]. However, currently the projected population of the study area as of 2017 was estimated 21,134,988[16].

\section{Research Method and Design}

The study employed mixed research method, consisting of both quantitative and qualitative research methods in order to avoid the drawbacks of each method. Where, quantitative methods fail to capture respondents' in-depth understanding in discussion. The data collection involves gathering both numeric information (questionnaire) as well as text information (interviews) so the final database represents both quantitative and qualitative information. In mixed research, the qualitative and quantitative parts of a study can be conducted concurrently (conducting both parts at roughly the same time) or sequentially (conducting one part first and then the second) to address a research question or a set of related questions [17]. Then, taking this into account and considering the nature of the project, concurrent parallel research design was applied for the purpose of addressing different research questions and for the sake of complementarily sets of quantitative and qualitative data.

\section{Data Sources and Data Types}


For this study both primary and secondary sources were employed to obtain necessary information and required data. Hence, primary sources included survey respondents, interviewees, key informants and focus group discussion participants to obtain primary data. While, secondary sources such as books, journals and annual reports relating to with the research problem or in direct relation to the study are included to obtain secondary data.

\section{Data Collection Methods /Instruments}

Survey questionnaires, interview, key informant interviews and FGDs were the data collection instruments used to gather primary data as shown here under:

Survey Questionnaires: These composed of both closed and open-ended questions. It was prepared in English and translated into Amharic, the respondents' local language. Before the questionnaire was administered, the draft was evaluated and unnecessary details and vague questions removed. A pretest was conducted to detect any weakness in design and instruments, and to provide alternative data from sample respondents as well as to ensure the items questionnaires bear the same meaning to all respondents and to assess the average time required administering an instrument. Hence, a pilot test was carried out on randomly selected respondents.

Interview: Semi- structured interviews were employed to obtain the qualitative data about the factors that determine the reproductive health in Amhara Region. The interviewees were selected from women between the ages of (15-49), the reproductive age group in the study area. With the consent of the participants, they were recorded through note taking and tape recording. The time for each interview was determined based on the data saturation for the required information regarding the issues raised.

Focus Group Discussions (FGD): A focus group discussion was carried out in each of the selected zones of Amhara region involving seven to twelve participants. Issues addressed in the focus group discussions for triangulation purposes were obtained from household survey and interviews. The group discussions were conducted via Amharic language, the medium of communication in the area with an assistant active note taker trained in proper orientation on how to organize research notes. The researchers acted as moderators during the discussions. Notes were taken from group discussions were summarized and any key and important issues arising in one group discussion used for further discussion in the following group discussions of study area.

Key Informant Interviews: These attempts to explore facts on the grounds of a rational approach to include key informant interviews by involving selected groups of individuals likely to provide needed information, ideas and insights on the proposed research. The informants were selected based on the position they have as woreda health office officials, zonal health department officials, regional health bureau officials, health extension workers from selected zones, regional bureau of women and children affairs officials, zonal women and children affairs department officials and woreda office of women and children affairs officials. The time and place for key informant interview' was decided by the key informants themselves and the majority of interviews were held in the place they selected. 
Document Review: These were used as a data collection method for evaluation and analysis of policy and strategies, case reports and legal instruments. Therefore, document reviews were also an important secondary data gathering tools. Giving due emphasis to assess the legal instruments, policies and strategies, programs about sexual and reproductive health, and gender issues in health in Amhara region and in Ethiopia in general as well as supplementing the statistical results in particular.

\section{Sampling Techniques and Sampling Procedures}

As the study targets both quantitative and qualitative methodologies, probability and non-probability sampling techniques employed to select the respondents/participants. The researchers were employed multi-stage sampling techniques. In the first stage, random sampling selected zones in Amhara region. Hence, North Gondar, East Gojjam, West Gondar zone, North Wollo and Awi special zone were selected. In similar ways, woredas from selected zones were selected randomly. So, a total of 10 woredas, two from North Gondar zone, three from East Gojjam zone, two from South Gondar zone, two from North Wollo zone, and one woreda from Awi special zone were selected represent zones on the basis of size of woredas' in each zone.

In the second stage, stratified random sampling was employed to select kebeles (small administration unit); because the woredas' of Amhara region categorized into three agro- ecological zones of WoyinaDega, Dega and Kolla. From these, sample kebeles were selected randomly by taken agro- ecology into account. In the third stage, stratified random sampling was employed to select male and female-headed households from each kebele. Proportional stratified random sampling was employed in accordance with the size of the kebele, then, each kebele's list of male and female-headed households were used as a sample frame. Finally, systematic random sampling technique was applied to select sample respondents from each kebele based on the lists obtained from the respective kebele's administration office.

\section{Sample Size Determination}

There are a number of strategies in determining a sample size, here; the researchers used formula based on the real context of the study. As the exact number of the study population is not clearly known, the researchers obtained to apply the precision of estimation of an unknown population for sample size determination. As quoted by[18;19] suggested the most commonly used formula for a questionnaire survey studies sample size determination when the population is large, indefinite and the needed representative sample is to analyze proportion. (see Formula 1 in the Supplementary Files)

Where, $\mathrm{n} 0=$ the required numbers of sample

$z=$ the value of the desired confidence level or confidence interval $(95 \%=1.96)$

$\mathrm{e}=$ the desired level of margin error or precision

$p=e s t i m a t e d$ variability or proportion of an attribute in the population $(50 \%=0.5)$ 


$$
q=1-p
$$

Accordingly, the researchers used 95\% confidence level $(z=1.96)$, the maximum variability among the population (50\%), and $5 \%$ margin of error/precision by looking at the expected criteria. When we apply the formula, (see Formula 2 in the Supplementary Files)

The researchers expected a 10\% non-response rate for this study. 38 respondents were included. The required sample sizes of this study were 422 women. However, seven questionnaires were not returned for further analysis. 415 questionnaires were used in the analysis.

\section{Data Analysis}

Both quantitative and qualitative data analysis techniques were employed. For quantitative method, upon completion of the data collection, the data is coded, edited and entered into the SPSS (Statistical Package for Social Science) version 20 and then the data analyzed through descriptive statistics(frequency and percentage) and inferential statistics(regression model analysis). A Chi-square test was also used to examine the association of variables and the qualitative data collected through key informant's interviews, focus group discussions and interview was analyzed textually to complement the statistical results. In other words, the qualitative data was analyzed by identifying key themes after transcribed, translated and coded raw data.

\section{Issues of Reliability, Validity and Trustworthiness of the Study}

The researchers conducted a pre-test among 30 respondents from selected study area before the execution of actual study to assure the reliability of the study. A Chronbach alpha was also employed to measure the internal consistency of the instrument or to test the reliability of the study. Therefore, the reliability of test statistics to all questions was checked using Chronbach Alpha with in the value of alpha $>0.75$ : i.e. 0.801. The researchers employed multiple source of information, established a chain of evidence, and had key informants' review reports for assuring the validity of the study. A copy of the questionnaires was peer reviewed to examine the items, and number of questions and measure the concept or construct of interest (content validity). Experts added some constructive ideas to improve the structured questionnaires and discussion guides, thus, some useless, repeated or redundant and ambiguous items were omitted. In addition, to achieve the trustworthiness of the study, the investigators employed triangulation via data sources, and description to convey finding and to complement statistical results with the qualitative part of the study. The findings and results of the study were interpreted in relation to the review of the literature and previous study for the purpose of analytical generalization.

\section{Ethical Considerations}

The issue of ethics is a critical concern in research. Different ethical principles were considered throughout data collection procedures. Firstly, the investigators took permission letters from the University of Gondar research and community service affairs vice president office, regional health bureau and zone department, bureau of women and children's' affairs, the authority of administrators in each 
district and health office. Secondly, consent was ensured with the participants and respondents to gain permission in order to conduct discussions and complete questionnaires ethically via describing the objective of the study and using the Amharic language enabling every participant and respondent to understand and be aware that all data collected from them was used only for academic purposes. In addition, ethical clearance was attached corresponding with the cover page of the questionnaire to clarify the purpose of the study and data were handled confidentially. Participants/respondents were also informed that the identity of the participants should not be written in the study document. Suitable places and times were chosen according to their suggestions. The researchers gave guarantees of the right to participate voluntarily and withdraw at any time during discussions. Furthermore, the key informants have been contacted by the letter of cooperation written by the authority and institution. The researchers properly paraphrased all literature and acknowledged all those consulted in this study.

\section{Results}

The result and discussion part of this research deals with women's awareness and knowledge of the nexus between violence and reproductive health problems, and awareness about the types of gender based violence which leads to reproductive health problems in the study area. It also included the demographic, individual, relational, community and society characteristics of the respondents in the study area. The awareness and perception of respondents towards the nexus between genders based violence and a reproductive health problem was also discussed through frequency and percentage. To know the categorical explanatory variables (demographic, individual, relation, community and society factors) to dependent variable (reproductive health problem due to violence), a Chi-square test was employed.

\section{Demographic Characteristics of the Respondents in the Study Area}

\section{Age, Age of first marriage, Duration in Marriage, Number of desired Children and Actual number of Children of Respondents}

Regarding the age of the respondents, the minimum age lies at 19 and the maximum at 45 . While the range of the age 26 with the standard deviation of 9.514. The data revealed the age of the respondents was concentrated in the adult age group (26). The study also shows the respondent's age of first marriage with a mean of 18.96 years old and the maximum of 40 . Implying that, most respondents were first married at an average of 18 years old. In the case of duration of marriage, respondents reported a minimum of 1 year and maximum of 40 years of marriage. The study also showed respondents were willing to have children at the maximum of 15 and an average or mean age of 5.57. Similarly, respondents responded their actual number of children with the mean of 3 and maximum of 12 children in the study area (See Table.1). These findings infer that respondents were at least 18 years of age, with a mean age of 18 for their first marriage, an actual number of children with mean of 3 and are willing to have a large number of children. 
Table.1 Respondents response to their age, age of first marriage, duration in marriage, desired number of children and actual number of children of respondents(N=415)

\begin{tabular}{|l|l|l|l|l|l|l|}
\hline S/n & Options & Minimum & Maximum & Mean & Range & Std. Deviation \\
\hline 1 & Age & 19 & 45 & 26.7446 & 26 & 9.51466 \\
\hline 2 & Age of First marriage & 22 & 40 & 18.9639 & 18 & 4.79544 \\
\hline 3 & Duration in marriage & 1.00 & 40 & 13.6627 & 39 & 10.12325 \\
\hline 4 & The number of children for future & 0.00 & 15 & 5.5732 & 15 & 2.27364 \\
\hline 5 & Number of children & 0.00 & 12 & 3.2120 & 12 & 2.10551 \\
\hline
\end{tabular}

Source: Obtained from survey data, 2019

\section{Residences of the Respondents in the Study Area}

Considering the place of respondents', $59 \%$ of the respondents live in rural areas, while $41 \%$ live in urban areas. This infers the majorities of the respondents were concentrated and reside in rural parts of the area (See Table, 2). However, the remaining less than half reside in urban sites. The place of residence may influence the reproductive health of the women. The chi-square test also showed there was a statistically significant association between a women's place of living or residence and their reproductive health with alpha value of 0.006 , which is significant at $\mathrm{P}<0.05$.

Table .2 Respondents residence or place of living $(\mathrm{N}=415)$

\begin{tabular}{|l|l|l|l|}
\hline Options & Frequency & Percentage & \\
\hline Rural & 245 & 59 & .006 \\
\cline { 1 - 3 } Urban & 170 & 41 & \\
\hline
\end{tabular}

Source: Obtained from survey data, 2019

\section{Religious status of the Respondents in the Study Area}

As Table.3 shows, a significant number of respondents (89.6\%) were orthodox, with few (0.7) being protestant. $9.4 \%$ Muslim and $0.2 \%$ catholic. This showed a majority of orthodox believers, which may have an influence on their reproductive health. This is due to the religion affiliation possibly hindering or improving the reproductive health aspects of women in the study area. But, the chi-square test showed no statistically significant association between women's religious affiliations and their reproductive health with alpha value of 0.572 , which is insignificant at $P<0.05$.

Table. 3 Respondents religious affiliations $(\mathrm{N}=415)$ 


\begin{tabular}{|l|l|l|l|}
\hline Options & Frequency & Percentage & \\
\hline Orthodox & 372 & 89.6 & \\
\hline Protestant & 3 & 0.7 & \multirow{2}{*}{.572} \\
\hline Catholic & 1 & 0.2 & \\
\cline { 1 - 2 } Muslim & 39 & 9.4 & \\
\hline
\end{tabular}

Source: Obtained from the survey data, 2019

\section{Educational Status of the Respondents in the Study Area}

As can be seen in Figure.1, the majority of the respondents (38.5\%) were not illiterate, while $23.61 \%$ of the respondents are able to read and write. The study also revealed that $17.3 \%$ of respondents have had a primary education and $5 \%$ a secondary education. In a similar manner, the findings pointed out that 12.2 $\%$ diploma, and $6.7 \%$ have a degree and above. This infers a significant number of respondents were not literate which hinders the improvement of reproductive health conditions as there is not adequate knowledge to keep and protect their physical, psychological and social aspects of reproductive health in a well manner. Women who have a diploma and degree or above are more likely protect their reproductive health than women who have no formal education. The absence of education hinders the improvement of reproductive health (physical, sexual, mental and psychological and social health) of women in the study area. In order to see whether there is an association between women's educational status and their reproductive health issues, chi-square test was employed. The result showed a significant association ( $=13.721, d f=5, p=0.017, p<0.05)$.

\section{Working Conditions of Respondents in the Study Area}

As can be seen in Table 4, nearly half the respondents (46.5\%) were farmers, $14 \%$ were government employment. The study also showed that $3.6 \%, 3.6 \%$ and $5.8 \%$ were private employees, housewives and daily laborers respectively. $10.4 \%$ and $16.1 \%$ were traders and employed in other tasks. From the above findings, it can be inferred the majority were working as farmers. However, few respondents were employed as housewives and daily laborers. The chi-square test also showed a statistically significant association between current working status type and reproductive health with alpha value of 0.041 , which is significant at $P<0.05$.

Table.4 Respondents current working status $(\mathrm{N}=415)$ 


\begin{tabular}{|l|l|l|l|}
\hline Options & Frequency & Percentage (\%) & \\
\hline Farmer & 193 & 46.5 & \\
\cline { 1 - 3 } Government employment & 58 & 14.0 & \\
\cline { 1 - 3 } Private employment & 15 & 3.6 & \multirow{2}{*}{.041} \\
\hline House wife & 15 & 3.6 & \\
\cline { 1 - 3 } Daily laborer & 24 & 5.8 & \\
\cline { 1 - 3 } Trade & 43 & 10.4 & \\
\hline Others & 67 & 16.1 & \\
\hline
\end{tabular}

Source: Obtained from survey data, 2019

Regarding the availability of their own work, the majority of the respondents (54.5\%) had their own work, while $45.5 \%$ worked for other people (See Table,5). Showing that for a significant number of the respondents their own work is the means of sustaining their daily life and income generation for family consumption in a given period of time. The chi-square test showed no statistically significant association between women's working for themselves and their reproductive health with alpha value of 0.163 , which is insignificant at $\mathrm{P}<0.05$.

Table.5 Respondents working for themselves $(\mathrm{N}=415)$

\begin{tabular}{|l|l|l|l|l|}
\hline \multicolumn{2}{|c|}{ Options } & Frequency & Percentage (\%) & \\
\hline \multirow{2}{*}{ Do you have your own work at time? } & Yes & 226 & 54.5 & 0.163 \\
\cline { 2 - 4 } & No & 189 & 45.5 & \\
\hline
\end{tabular}

Source: Obtained from survey data, 2019

\section{Awareness and Knowledge of Women of the Nexus between Genders based Violence and Reproductive Health Problems in the Study Area-Amhara Region}

\section{Awareness about GBV types and its effects on Reproductive Health in the Study Area}

As Table. 6 shows, $40 \%$ of the respondents reported they have an awareness regarding gender based violence and its effects on reproductive health, the study also shows $60 \%$ of the respondents have no awareness about the relationship. This indicates the need for further work about the causes, forms and consequences of gender based violence for the community to address the problems of GBV that lead to serious reproductive health problems especially in the study area-Amhara Region.

Table.6 Respondents for awareness about GBV types and its problems for Reproductive Health in the study area ( $\mathrm{N}=415)$

\begin{tabular}{|l|l|l|l|}
\hline Variables & Options & Frequency & Percentage (\%) \\
\hline Do you know GBV types that lead to RH problem in your community? & Yes & 166 & 40.0 \\
\cline { 2 - 4 } & No & 249 & 60.0 \\
\hline
\end{tabular}




\section{An Awareness and Perception about Reproductive Health Problems due to GBV in the Study Area}

Regarding the awareness of the reproductive health problems due to gender based violence, $55.9 \%$ of the respondents reported an awareness of the relationship, while $44.1 \%$ of the respondents responded no awareness of it (See Table, 7). From this finding, one can understand that women are aware of the nexus between $\mathrm{RH}$ problems and gender based violence in the study area.

Table.7 Respondents awareness on reproductive health problems which comes due to violence in the study area $(\mathrm{N}=415)$

\begin{tabular}{|c|c|c|c|}
\hline Variables & Options & Frequency & $\begin{array}{l}\text { Percentage } \\
(\%)\end{array}$ \\
\hline \multirow{2}{*}{$\begin{array}{l}\text { Do you know the reproductive health problems due to violence in } \\
\text { your community? }\end{array}$} & Yes & 232 & 55.9 \\
\hline & No & 183 & 44.1 \\
\hline
\end{tabular}

Source: Obtained from survey data, 2019

\section{Awareness of Physical Reproductive Health Problems due to GBV in the Study Area}

Concerning their awareness of the issue, a significant number of respondents (40.5\%) are aware headaches can be significant of GBV, $(29.6 \%)$ of the respondents are aware of functional limitation and disability due generally to gender based violence in the study area (See Table.8). The study also shows that gastrointestinal disorders and premature mortality are reported by $28.2 \%$ and $27.2 \%$ of the respondents respectively. In a similar manner, $26.5 \%$, and $25.8 \%$ of the respondents reported they aware concerning the problem of fatigue and immediate physical injuries (to head, ear, teeth, lacerations, burns, fractures, homicides...) in the study area. However, $15.4 \%, 26.3 \%, 28.7 \%$, and $30.1 \%$ of the respondents have no awareness of the problems of headache, functional limitation and disability, premature mortality and immediate physical injuries ( to head, ear, teeth, lacerations, burns, fractures, homicides...) respectively. All this shows a majority of the respondents are aware of the problems of headaches, functional limitations and disability, and gastro intestinal disorder, while a significant number of respondents have no awareness of the problem of premature mortality and immediate physical injuries.

Table.8 Respondents awareness of physical reproductive health problems due to GBV in the study area (N=232) 


\begin{tabular}{|l|l|l|l|}
\hline Physical Reproductive health problems due to GBV & Options & Frequency & $\begin{array}{l}\text { Percentage } \\
\text { (\%) }\end{array}$ \\
\hline $\begin{array}{l}\text { Immediate injuries to (head, ear, teeth, lacerations, burns, fractures, } \\
\text { homicides...) }\end{array}$ & Yes & 107 & 25.8 \\
\cline { 2 - 4 } & No & 125 & 30.1 \\
\hline \multirow{2}{*}{ Headache } & Yes & 168 & 40.5 \\
\cline { 2 - 4 } & No & 64 & 15.4 \\
\hline Fatigue & Yes & 110 & 26.5 \\
\cline { 2 - 4 } & No & 122 & 29.4 \\
\hline Functional limitation and disability & Yes & 123 & 29.6 \\
\cline { 2 - 4 } & No & 119 & 26.3 \\
\hline Gastrointestinal disorders & Yes & 117 & 28.2 \\
\cline { 2 - 4 } & No & 115 & 27.7 \\
\hline Premature Mortality & Yes & 113 & 27.2 \\
\cline { 2 - 4 } & No & 119 & 28.7 \\
\hline
\end{tabular}

Source: Obtained from survey data, 2019

$\mathrm{N}: \mathrm{B}:-T h e$ multiple responses were recorded among the respondents who know the reproductive health problems that comes due to violence $(\mathrm{N}=232)$

\section{Awareness and Perception on Psychological/Mental Health Problems due to GBV}

As can be seen in Table.9, $39 \%$ of the respondents are aware of the problem of depression and anxiety, while $35.7 \%$ of the respondents reported awareness about post-traumatic stress disorder in the study area. The study also shows $34.9 \%$, and $28.9 \%$ of the respondents have an awareness about the problem of low self-esteem, and eating and sleeping disorders. Additionally, among psychological and mental health problems, $22.2 \%, 20.7 \%, 16.4 \%$, and $14.2 \%$ of the respondents reported being aware of the problem of alcohol and substance abuse, obesity or anorexia, sexual risk taking and unsafe sexual behavior, aggression and violence due to gender based violence in the study area respectively. However, $41.7 \%, 39.5 \%, 35.2 \%, 32.7 \%$ of respondents said they have no awareness regarding the problems occurred as a result of gender based violence.

Similarly, $27 \%, 21 \%, 20.2 \%$ and $16.9 \%$ of the respondents reported no awareness of the problem of eating and sleeping disorders, low self-esteem, and post-traumatic stress disorder due to violence in the study area respectively. From the above result, it can be deduced the majority of the respondents have awareness about the problems of depression, anxiety, and post traumatic disorder, while a significant number have no awareness of these problems in the study area.

Table.9 Respondents awareness on psychological and/mental health problems due to GBV in the study area $(\mathrm{N}=232)$ 


\begin{tabular}{|l|l|l|l|}
\hline Psychological/mental health problems due to GBV & Options & Frequency & Percentage (\%) \\
\hline \multirow{2}{*}{ Depression and Anxiety } & Yes & 162 & 39.0 \\
\cline { 2 - 4 } & & & \\
\cline { 2 - 4 } & No & 70 & 16.9 \\
\hline \multirow{2}{*}{ Eating and sleeping disorders } & Yes & 120 & 28.9 \\
\cline { 2 - 4 } & No & 112 & 27.0 \\
\hline \multirow{2}{*}{ Low self esteem } & Yes & 148 & 35.7 \\
\cline { 2 - 4 } & No & 84 & 20.2 \\
\hline \multirow{2}{*}{ Alcoholic and Substance abuse } & Yes & 145 & 34.9 \\
\cline { 2 - 4 } & No & 87 & 21.0 \\
\hline Obesity or Anorexia & Yes & 92 & 22.2 \\
\cline { 2 - 4 } & No & 140 & 32.7 \\
\hline Aggression \&Violence & Yes & 86 & 20.7 \\
\cline { 2 - 4 } & No & 146 & 35.2 \\
\hline Sexual risk taking and unsafe sexual behavior & Yes & 59 & 14.2 \\
\cline { 2 - 4 } & No & 173 & 41.7 \\
\cline { 2 - 4 } & Yes & 68 & 16.4 \\
\hline
\end{tabular}

Source: Obtained from survey data, 2019

\section{An Awareness and Perception on the Sexual and Reproductive Health Problems due to Violence in the Study Area}

Table.10 demonstrates that $36.1 \%$ of the respondents reported awareness about STI (Sexual Transmitted Diseases) and HIV/AIDS (Human Immune Virus Acquired Immune Deficiency Syndrome), while $19.8 \%$ of the respondents reported no awareness of STI/AIDS from violence. The study also shows that unwanted pregnancy, fetal injuries and cervical cancer issues reported by $31.3 \%, 25.5 \%$ and $25.3 \%$ respondents due to their awareness of these issues, while $24.6 \%, 30.4 \%, 30.6 \%$ of the respondents reported no awareness of them.

$27.2 \%, 26.9 \%$ and $23.6 \%$ of the respondents reported an awareness of the problems of maternal, neonatal and infant mortality, abortions (safe and unsafe),and others problem apart from sexual health problems that might be occurred due to gender based violence in the study area. However, $28.7 \%, 29 \%$, and $32.3 \%$ of the respondents reported no awareness about these issues. From the study's results, it can be understood that most of the respondents are aware of STI/ AIDS, and unwanted pregnancy problems, on the other hand they are not aware of the problems of cervical cancer, fetal injuries, maternal, neo natal and child mortality, and abortions apart from sexual health problems possibly due to violence against women in the study area.

Table.10 Respondents awareness on sexual and reproductive health problems due to Violence against women in the study area $(\mathrm{N}=232)$ 


\begin{tabular}{|l|l|l|l|}
\hline Sexual and reproductive health problems due to GBV & Options & Frequency & Percentage (\%) \\
\hline \multirow{2}{*}{ Fetal Injuries } & Yes & 106 & 25.5 \\
\cline { 2 - 4 } & & & \\
\cline { 2 - 4 } & No & 126 & 30.4 \\
\hline \multirow{2}{*}{ STI/ HIV/AIDS } & Yes & 150 & 36.1 \\
\cline { 2 - 4 } & No & 82 & 19.8 \\
\hline \multirow{2}{*}{ Cervical Cancer } & Yes & 105 & 25.3 \\
\cline { 2 - 4 } & No & 127 & 30.6 \\
\hline \multirow{2}{*}{ Unwanted pregnancy } & Yes & 130 & 31.3 \\
\cline { 2 - 4 } & No & 102 & 24.6 \\
\hline \multirow{2}{*}{ Abortions (safe and unsafe) } & Yes & 114 & 26.9 \\
\cline { 2 - 4 } & No & 118 & 29 \\
\hline \multirow{2}{*}{ Maternal, neonatal \& infant mortality } & Yes & 113 & 27.2 \\
\cline { 2 - 4 } & No & 119 & 28.7 \\
\hline \multirow{2}{*}{ Others } & Yes & 98 & 23.6 \\
\cline { 2 - 4 } & No & 134 & 32.3 \\
\hline
\end{tabular}

Source: Obtained from survey data, 2019

\section{Discussion}

As finding of this study demonstrated, $40 \%$ of the respondents reported they have awareness regarding gender based violence and its effects on reproductive health, while $60 \%$ have no awareness about the relationship. On the level of understanding on the issue of gender-based violence, most of the students who are understood about gender-based violence will aware on the problem. In other hand, if such problem occurs, they know what should be done to handle the situation. The number of cases of the occurrence of gender-based violence also contributed to the awareness on gender-based violence. Nowadays, there are increase numbers of cases on gender-based violence reported in mass media that lead students aware about the cases. Indirectly, when there is increasing number of cases so they will try to take care of themselves especially when they are going for outing [20]

In the findings reported by [21] the improvement was largely due to a change among young men, from $48 \%$ having a high level of attitudinal support for violence in 2009 to $38 \%$ in 2013 . The Government of Sweden noted that GBV is more prevalent in patriarchal societies with rigid notions of manhood, weak institutions, poor access to information and poor reinforcement of human rights; societies where violence is socially accepted as a means to settle inter-personal disputes[22]. A study conducted on reproductive health among women in three communities around Beirut, Lebanon, as part of the reproductive health component of a larger Urban Health Study. The women's understanding of good reproductive health included three major themes, which were expressed differently in the three communities. Their understanding included good physical and mental health, and underscored the need for activities promoting health. Their ability to reproduce and raise children, practice family planning and birth spacing, and go through pregnancy and motherhood safely were central to their reproductive duties and their social status. Finally, they saw reproductive health within the context of economic status, good marital relations and strength to cope with their lives [23]. 
Concerning their awareness of the issue, a significant number of respondents (40.5\%) are aware headaches can be significant of GBV, $(29.6 \%)$ of the respondents are aware of functional limitation and disability due generally to gender based violence in Amhara region. They understand on the causes on GBV and have their own perception toward this issue. Gender-based violence is a worldwide problem, but in order to better understands the patterns of violence and its causes and, hence, to eliminate them, the starting point should be knowledge of the particular historical and socio-cultural factors at work in each specific context. The specific nature of gender-based violence in the home is such that other, apparently less serious forms of behavior may also be identified as acts of violence; these types of conduct include verbal and coercion, the infliction of physical injuries not severe enough to constitute serious bodily harm, and sexual abuse that does not constitute rape or ravishment [20].

The findings of this study stipulated that, $27 \%, 21 \%, 20.2 \%$ and $16.9 \%$ of the respondents reported no awareness of the problem of eating and sleeping disorders, low self-esteem, and post-traumatic stress disorder due to violence in Amhara region respectively. However, little research is available on women's own perceptions of their mental health or on their health priorities. For women themselves, mental health is critically important. One study reported that women's interest in mental health concerns actually outweighed their interest in reproductive health [24]. Confirming the above findings, the study showed that the result of women's perceptions of intimate partner violence (IPV) as $82.2 \%$ of the women were quite aware of IPV and 76.1\% were concerned when heard about IPV. However, 78.5\% were of the opinion that violence between married, dating or ex-partners is a personal matter between them and no one should interfere or report the violence [25]. A study reported by Central Statistical Agency (CSA) [Ethiopia] and ICF indicated, the information on sexual behavior is important in designing and monitoring intervention programs to control the spread of HIV. It is recognized that some respondents may have been reluctant to provide information on recent sexual behavior [26].

Lack of clear understanding and misperceptions about SRH combined with unsupportive cultural expectations about sexual life remain important constraints to young people's efforts of seeking such services. Absence of confidentiality, lack of privacy, feeling of shame, being identified by parents and health system factors such as lack of SRH services plus long waiting time were also important barriers to using SRH. Thus, SRHS programs for young people must address psycho-social, sociocultural and health service factors through culturally sensitive SRH education and service delivery approaches. So, an inclusive approach which involves parents is recommended in SRH education program [27]. Confirming of this result, a study findings indicates that that if students are aware with gender-based violence including sexual harassment, rape, incest, domestic violence, violence against women, date rape and violence against disable person, the possibilities of this issue might occur in future is lower. It is because, when they alert about the issue they can try as can as possible to avoid becoming a victims by taking necessary steps to safe themselves. In addition, those who really understand about the issues of genderbased violence, it may indirectly reduce the number of cases [20].

The findings point to the need to situate interventions in the life course of women, their health and that of their husbands and families; the importance of reproduction not only from a health services point of view, 
but also as regards women's roles and responsibilities within marriage and their families; and taking account of the harsh socio-economic conditions in their communities [23]. The strongest knowledge concerning HIV prevention was found in Namibia and the weakest in Malawi and Mozambique.

Knowledge of HIV prevention increased with education Attitudes towards violence against women were tolerant: in Mozambique and Zambia, for example, the majority of women stated that there are reasons that justify a husband hitting or beating his wife. A substantial proportion of women had experienced physical violence after the age of 15 . In Zambia, $47 \%$ of all women had experienced physical violence and $20 \%$ had experienced sexual violence, and more than half of ever-married women reported having experienced emotional, physical or sexual violence at the hands of their partner [28].

\section{Conclusion}

An inability to deal with reproductive health problems at any stage in life may set the scene for later health problems. Evidence has shown that at least $60 \%$ of women globally are exposed to reproductive health $(\mathrm{RH})$ problems related to gender based violence than their male counter parts. Such exposure to reproductive health problems is contrary to the definition of human rights which stipulates that universal respect for and observance of human rights and the fundamental freedoms for all without discrimination as to race, sex, language, or religion. There is widespread GBV in the world in the form of physical abuse, rape and forced marriages. These forms of violence negatively impact on women's reproductive health, yet a culture of silence (largely precipitated by socio-cultural, economic, religious and policy implementation) encase the subject of GBV. The findings from this research show that different forms of gender based violence committed on women impacts on women's reproductive health. So, the reproductive health of women is the outcomes of different gender based violence. Hence, evaluating the knowledge and awareness on those $\mathrm{RH}$ problems due to gender based violence needs an attention especially in Amhara Region. The findings regarding the awareness about GBV types and their impacts on reproductive health in the study area demonstrated that, $40 \%$ of the respondents reported an awareness regarding the gender based violence and its impact on reproductive health. The study also demonstrated $60 \%$ of the respondents have no awareness about the relationship between gender based violence and reproductive health problems. Therefore, as a result of this study finding, it can be inferred the majority of the respondents reported no awareness about the types of gender based violence which leads to reproductive health problems in the study area.

However, concerning the awareness about the reproductive health problems due to gender based violence, $(55.9 \%)$ of the respondents reported awareness about the reproductive health problems due to violence, while $44.1 \%$ of the respondents responded no awareness of the issues. Concerning awareness to the physical reproductive health problems due to gender based violence, a significant number of respondents $(40.5 \%)$ are aware of the problems of headaches, $(29.6 \%)$ of the respondents are aware of functional limitation and disability due to gender based violence in the study area. From the psychological/mental health problems due to GBV, $39 \%$ of respondents reported being aware of the problem of depression and anxiety, while $35.7 \%$ of the respondents reported awareness about posttraumatic stress disorder in the study area. 
Regarding an awareness and perception of the sexual and reproductive health problems, $(36.1 \%)$ of the respondents reported being aware of STI (Sexual Transmitted Diseases) and HIV/AIDS (Human Immune Virus Acquired Immune Deficiency Syndrome), while $19.8 \%$ of the respondents have no awareness of STI/AIDS from violence. The study also showed that unwanted pregnancy, fetal injuries and cervical cancer problem reported by $31.3 \%, 25.5 \%$ and $25.3 \%$ respondents due to their awareness of the relationship. From the study findings, a significant number of respondents have awareness about physical health problems rather than psychological and sexual reproductive health problems. From the above study findings, we can understand that women have awareness about the reproductive health problems, but they have little awareness about gender based violence that causes $\mathrm{RH}$ problems in the study area.

\section{Recommendations}

The following points were forwarded as the basic elements to address gender-based violence in all sexual and reproductive health situations in the study area for all concerned bodies.

- The health care sector must take a significant impact on publicizing and addressing violence against women, and on reducing the reproductive health problems related to abuse/violence.

- Training and education must be expanded about the types or forms of GBV and its consequences as well as the psychological and sexual reproductive health problems in the study area. With training and support from program managers, health care providers can learn to identify and care for women who have experienced violence. For screening to be useful, providers must be well trained in how to ask about and respond to abuse, and be prepared to help survivors of abuse with treatment and referral. They must learn to work with agencies in other sectors.

- Changing people's behavior and attitudes towards violence requires long-term commitment. Community health care workers and other influential health providers must take the lead in introducing awareness and behavior change in the community. Create a community based response to violence must be created by stimulating discussions, educating community members about the costs and consequences of abuse, and advocating for nonviolent relationships. Exposing violence and enabling vulnerable and marginalized people to receive necessary services will help break the life cycle of violence and promote the rights of women and girls.

- Increasing women's economic empowerment is still crucial for longer term prevention of GBV. Women's economic empowerment interventions which also address gender norms and reach couples and communities can reduce such risks. As influential community leaders, health care professionals -women and men-have important roles to play in promoting violence prevention in the community. They can gain the support of other community leaders.

\section{Abbreviations}

GBV: Gender Based Violence; FGM/C: Female Genital Mutilation or Cutting; FGD: Focus Group Discussion; GOF: Goodness of Fitness; HTP: Harmful Traditional Practices; SIDA: Swedish International 
Development Agency; RC: Reference Category; RH: Reproductive health; WHO: World Health Organizations; UN: United Nations; UNFPA: United Nations Fund for Population Agency; UNICEF: United Nations International Cultural and Educational Fund; USAID: United State Agency for International Development;

\section{Declarations}

\section{Ethics approval and consent to participate}

Ethical approval was obtained from University of Gondar Research and community service affairs V/president and College of Social Science and Humanities Research and community service affairs Committee and informed both oral and written consent was taken from every woman and their parents who participated in the study. Enumerators and invigilators approached well irrespective of ages, religion and ethnicity while conducted this study. The letter of cooperation which was written from University of Gondar, Regional health bureau and each administrative zone were attached in each cover pages of questionnaires where all of the respondents and participants were participated by known the aim of the study. Therefore, all respondents and participates provided their consent without any pressure due to this rationale they were decided to involved after knowing the objective of this study is for academic purpose solely.

\section{Consent for publication}

Not Applicable

\section{Availability of data and materials}

Data are available from the corresponding authors on reasonable request. Supplementary files also added to the editorial manager website while some of other supplementary documents were not shared to depositor for the sake of maintain confidentiality of our participants. Data supporting findings are available at the hand of Mr. Alemeneh Getaneh, who was coordinator of this study.

\section{Competing of interests}

The authors have declared, there is no conflict of interest regarding the concepts and methodological parts of the study.

\section{Funding}

The study was done through provided funds from University of Gondar Research and Community service affairs Vice president Office in 2018/2019.

\section{Authors Contributions}


EK and $A G$ are the major contributor of the proposal development and analysis of the article. EK, SA, and AG facilitated the data collection processes of the manuscript in the study area. All authors conducted the analysis and interpretation of the manuscript. The authors conducted the selection of available studies for systematic review, drafted the first structure of the study, read and wrote based on the guidelines and the standards of the journals. Finally, all procedures and tasks throughout the development of the manuscript have been carried out by the authors' collaboratively.

\section{Acknowledgements}

First of all, we would like to express our deepest gratitude to the study participants for being willing to participate in this study without whom this research would have not been realized. Secondly, the authors would like to acknowledge the University of Gondar for providing financial support to conduct this research. Thirdly, we would like to thank the data collectors and supervisors for their unreserved work and contribution for the quality of the data. Last but not least, the authors would like to acknowledge and give deepest thanks to Ms. Judy Price for helping in the editing of the manuscript.

\section{Authors Information Details}

Eyayu Kasseye Bayu is a Lecturer at the Department of Gender and Development Studies, College of Social Sciences and Humanities, University of Gondar, Gondar, Ethiopia. Solomon Anteneh Tegegne is a lecturer at the Department of Gender and Development Studies, and a PhD candidate in Department of Environment and Development Studies, College of Social Sciences and Humanities, University of Gondar, Gondar. Alemeneh Getaneh Mihretie is a principal coordinator of the project and also a lecturer at the Department of Gender and Development Studies, College of Social Sciences and Humanities, University of Gondar, Gondar, Ethiopia..

\section{References}

[1]. UNPIN (United Nations Population Information Network)(2010).Guidelines on reproductive health. Geneva, Switzerland, United Nations Population Information Network (POPIN), 2002. Available at www. un.org/ popin/ unfpa /taskforce /guide/ iatfreph. gdl.html - accessed 22 June 2010

[2]. Collumbien M, Busza J, Cleland J, Oona Campbell (2010) Social Science Methods for Research on Reproductive Health. Geneva

[3]. Hilary Benn. (2004). Sexual and reproductive health and rights: A position paper Published by the Department for International Development, July 2004

[4]. UNICEF.(2013). Sexual and Gender-Based Violence against Refugees, Returnees and Internally displaced Persons-Guidelines for Prevention and Response

[5]. Tefera Darge, 2014. Gender Power Relations in Reproductive Decision-Making: The Case of Migrant Weavers of Addis Ababa, Ethiopia. Journal of Science \&Developement2 (1) 2014, 59-71 
[6]. Amaya, C. E. G., Acharya, A. K., \&Bonfiglio, J. M. I. (2016). Gender Based Violence and Reproductive Health of Indigenous Women in Mexico. Sociology Mind, 6, 107-113.

http://dx.doi.org/10.4236/sm.2016.63009

[7]. $\mathrm{MOH}$ republic of Tanzania (2011).Adolescence in Tanzania, Communication,Advocacy, and Partnership section, United republic of Tanzania, Dar es Salaam

[8]. Kaddour Afamia, Raghda Hafez,b Huda Zuraykc. (2005) Women's Perceptions of Reproductive Health in Three Communities around Beirut, Lebanon, Reproductive Health Matters, 13:25, 34-42, DOI: $10.1016 /$ S0968-8080(05)25170-4

[9]. WHO (2002). WHO (World Health Organization) 2002. Research on reproductive health at WHO: Biennial report 2000-2001: Health Organization; 2002.

[10]. Mengistu and Bogalech (2007). MengistuAsnake, and BogalechAlemu. (2007).Women's Empowerment in Ethiopia:New Solutions to Ancient Problems: Pathfinder International/Ethiopia

[11]. Zewdie Birhanu, Kora Tushune, Mulusew G. Jeben. Sexual and Reproductive Health Services Use, Perceptions, and Barriers among Young People in Southwest Oromia, Ethiopia. Ethiop J Health Sci.2017; 28 (1):37. doi: http://dx.doi.org/10.4314/ejhs.v28i1.6.

[12].Aynalem,Adugna(2014).AmharaDemographyandHealth,www.EthioDemographyAndHealth.Org [13]. CSA (2007). Tables: Amhara Region Archived November 14, 2010, at the Way-back Machine., Tables $2.1,2.5,3.1,3.2,3.4$.

[14]. CSA (2019/2010)."Households by sources of drinking water, safe water sources"Archived 2009-0305 at the Way-back Machine. CSA Selected Basic Welfare Indicators (accessed 28 January 2009)

[15]. Ahmed Mohammedand AbebawEshete(2014).Resources for Awareness of Population Impacts on Development (RAPID):The Case of Amhara Region

[16]. CSA (2018). CSA Population Projection of Ethiopia for All Regions At Wereda Level from 2014 2017. Federal Democratic Republic of Ethiopia Central Statistical Agency. Retrieved 4 June 2018.

[17].Stephen,Kwadwo Antwi.,and Kasim,Hamza.(2015). Qualitative and Quantitative Research Paradigms in Business Research: A Philosophical Reflection. European Journal of Business and Management. Vol.7, No.3. Ghana.

[18]. Amugune, B.K. (2014). Sample size Determination and Sampling Techniques, Mental Health Workshop, Maanzoni, 15 October 2014

[19]. Singh, Ajay. S., and Masuku, Micah. B. (2014). Sampling Techniques and Determination of Sample size in Applied Statistics Research: An overview. University of Swaziland, Luyengo, Swaziland, 
International Journal of Economics, Commerce and Management, Vol. II, Issue 11. United Kingdom

[20]. Zarina Mohd Zain. 2012. The Awareness on Gender-based Violence among Students in the Higher Learning Institutions; Procedia - Social and Behavioral Sciences 38 ( 2012 ) 132 - 140; Asia Pacific International Conference on Environment-Behaviour Studies, Grand MargheritaHotel, Kuching, Sarawak, Malaysia, 7-9December 2010

[21]. Harris, A, Honey, N, Webster, K, Diemer K \& Politoff, V 2015, Young Australians' attitudes to violence against women: Findings from the 2013 National Community Attitudes towards Violence Against Women Survey for respondents 16-24 years, Victorian Health Promotion Foundation, Melbourne, Australia.

[22]. The Government of Sweden (2009). Gender based violence, health and the role of the health sector. (2009).Developed with support from the Government of Sweden

[23]. Kaddour, Afamia, Hafez, Raghda \& Huda Zurayk. (2005) Women's Perceptions of Reproductive Health in Three Communities around Beirut, Lebanon, Reproductive Health Matters, 13:25, 34-42, DOI: $10.1016 /$ S0968-8080(05)25170-4

[24]. World Health Organization. 2009. Mental health aspects of women's reproductive health; a global review of the literature

[25]. Adriel Monkam Tchokossa, RN, Timothy Golfa, Omowumi Romoke Salau, RN MSsN; Adesola Adenike Ogunfowokan, Perceptions and Experiences of Intimate Partner Violence among Women in IleIfe Osun State Nigeria; International Journal of Caring Sciences January-April 2018 Volume 11 | Issue 1| Page 267.

[26]. Central Statistical Agency (CSA) [Ethiopia] and ICF. 2016. Ethiopia Demographic and Health Survey 2016: Key Indicators Report. Addis Ababa, Ethiopia, and Rockville, Maryland, USA. CSA and ICF

[27]. Zewdie Birhanu, Kora Tushune, Mulusew G. Jeben. Sexual and Reproductive Health Services Use, Perceptions, and Barriers among Young People in Southwest Oromia, Ethiopia. Ethiop J Health Sci.2017; 28(1):37.doi:http://dx.doi.org/10.4314/ejhs.v28i1.6.

[28]. Riikka Shemeikka, Scholastika lipinge, Nelago Indongo, Harri Siiskonen, Taina Torkko, Veijo Notkola.2009. Reproductive health in southern Africa: Government policies and changes in sexual and reproductive health and rights; Evaluation Reports; Arviointira portteja Rehabilitation Foundation Kuntoutussaatio $1 / 2009$

\section{Figures}




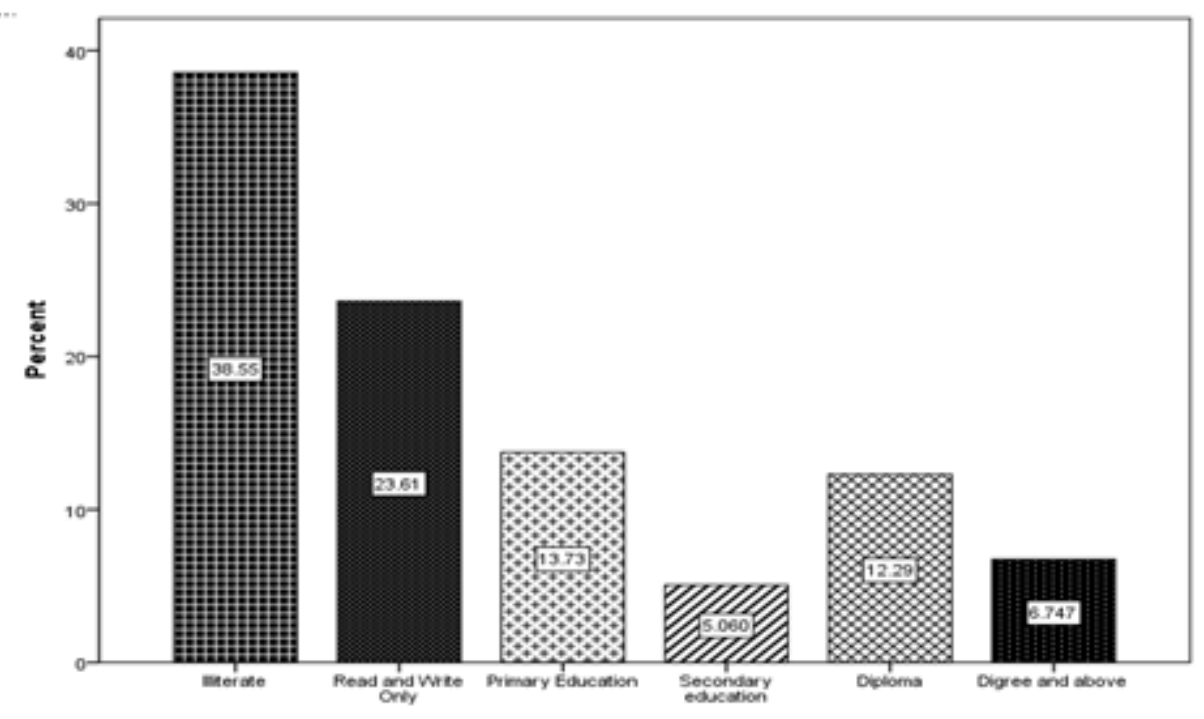

Figure 1

Respondents educational status ( $\mathrm{N}=415)$ Source: Obtained from survey data, 2019

\section{Supplementary Files}

This is a list of supplementary files associated with this preprint. Click to download.

- Formulas.pdf 